\title{
Performance measures of surgeon-performed colonoscopy in a Veterans Affairs medical center
}

\author{
H. S. Tran Cao $\cdot$ B. C. Cosman · B. Devaraj • \\ S. Ramamoorthy · T. Savides · M. L. Krinsky • \\ S. Horgan $\cdot$ M. A. Talamini $\cdot$ M. K. Savu
}

Received: 14 April 2008/Accepted: 12 January 2009/Published online: 6 March 2009

(c) The Author(s) 2009. This article is published with open access at Springerlink.com

\begin{abstract}
Background Quality indicators are increasingly emphasized in the performance of colonoscopy. This study aimed to determine the standard of care rendered by surgeonendoscopists in a Veterans Affairs (VA) medical center by evaluating the indications for colonoscopy and outcome performance measures according to established quality indicators for colonoscopy.

Methods A prospective standardized computer endoscopic reporting database (ProVation MD) was retrospectively reviewed. All colonoscopies performed by attending surgeons at the San Diego VA medical center between 1 January 2004 and 31 July 2007 were included in the study. Patients with charts that had incomplete reporting were excluded. The quality indicators used included the Society of American Gastrointestinal and Endoscopic Surgeons (SAGES) criteria for colorectal cancer screening, the American Cancer Society (ACS) guidelines for postcancer resection surveillance, and the American Society of
\end{abstract}

H. S. Tran Cao - B. C. Cosman - B. Devaraj - S. Ramamoorthy · S. Horgan - M. A. Talamini - M. K. Savu

Department of Surgery, University of California San Diego,

San Diego, CA 92103, USA

T. Savides · M. L. Krinsky

Department of Medicine, University of California San Diego,

San Diego, CA 92103, USA

B. C. Cosman · M. L. Krinsky · M. K. Savu ( $\square)$

Veterans Affairs Healthcare System, 3350 La Jolla Village

Drive, San Diego, CA 92161, USA

e-mail: michelle.savu@va.gov

Present Address:

M. K. Savu

University of Texas Health Science Center at San Antonio,

7703 Floyd Curl Drive, San Antonio, TX 78229, USA
Gastrointestinal Endoscopists (ASGE) quality indicators for colonoscopy.

Results The data for 558 patients $(96 \%$ men) were analyzed. The average patient age was 63 years (range, 2593 years). Almost all the colonoscopies (99\%) were performed in accordance with established criteria. The most common indications for colonoscopy were screening $(n=$ 143, 26\%), non-acute gastrointestinal bleeding $(n=127$, $23 \%)$, polyp surveillance $(n=100,18 \%)$, postcancer resection surveillance $(n=91,17 \%)$, abdominal pain $(n=$ $19,4 \%)$, and anemia $(n=14,3 \%)$. Postcancer resection surveillance colonoscopies were performed according to recommended criteria in $98 \%$ of the cases. The cecal intubation rate was $97 \%$, and the overall adenoma detection rate was $26 \%$. Two patients $(<1 \%)$ experienced complications requiring intervention.

Conclusion The study data indicate that surgeon-performed colonoscopies meet standard quality criteria for indications and performance measures. The authors therefore conclude that surgeon-endoscopists demonstrate proficiency in the standard of care for colonoscopy examinations.

Keywords Adenoma detection rate - Colonoscopy · Performance measures · Quality · Surgeon-endoscopist

Colonoscopy has a well-established role in the evaluation and treatment of colonic diseases, and in the hands of the surgeon, its use has centered around the screening, potential treatment, and surveillance of colorectal neoplasia. Currently, in light of the rapidly expanding field of minimally invasive surgery, especially with regard to recent advancements in natural orifice transluminal endoscopic surgery (NOTES), endoscopy_including colonoscopy- 
has the potential to take on a much greater role in a surgeon's practice. Alongside these developments, the Accreditation Council for Graduate Medical Education (ACGME) has increased the endoscopy requirements for surgical residents to a minimum of 85 total endoscopies, including at least 50 colonoscopies, by the time of their graduation [1].

Together with the recognized need for increased training of surgical residents, recent literature has focused on measurements used to determine proficiency and competence in the endoscopists' performance of colonoscopy. As a result, several guidelines and quality indicators for the performance of colonoscopies have been published, including criteria such as adenoma detection and cecal intubation rates [2]. In this study, we assessed the quality and competence of surgeon-endoscopists to perform colonoscopies at a Veterans Affairs (VA) medical center by measuring their performance outcomes according to established quality indicators.

\section{Materials and methods}

We performed a retrospective chart review of all colonoscopies performed between 1 January 2004 and 31 July 2007 by two attending surgeons (B.C.C., a colorectal surgeon, and M.K.S., a general and laparoscopic surgeon) at the VA medical center in San Diego, as reported in ProVation MD. Patients with charts that had incomplete reporting were excluded from the study.

For each colonoscopy, the following data were collected: age, gender, indication, findings (including the number and location of polyps when known), and pathology report. The data were compared with grade 1 recommendations for quality indicators proposed by the American Society for Gastrointestinal Endoscopy (ASGE) for colonoscopy [2] (Table 1) and with the postcancer resection surveillance guidelines from the American Cancer Society (ACS) [3] (Table 2). Screening guidelines were obtained from the Society of American Gastrointestinal and Endoscopic Surgeons (SAGES).

\section{Results}

From 1 January 2004 to 31 July 2007, a total of 558 colonoscopies were performed by two attending surgeons at the Veterans Affairs Healthcare System in San Diego, California. The mean age of the patients was 63.3 years (range, 25-93 years), with $89 \%$ of them older than 50 years. Most of the patients $(96 \%)$ were men.

The indications for the colonoscopies are presented in Table 3. Some patients had more than one indication for colonoscopy. Overall, $99 \%$ of the procedures were performed in accordance with the guidelines for appropriate indications established by ASGE [4]. Indications not in accordance with the standard guidelines included screening of four asymptomatic individuals younger than 50 years without a family history, workup of two patients with a small bowel obstruction, and workup of one patient with recurrent bacteremia of unknown source.

The cecum was successfully intubated with identification of landmarks in 541 (97\%) of 558 colonoscopies and in $143(98 \%)$ of 146 screening colonoscopies. The reasons

Table 1 Grade 1 recommendations for quality indicators for colonoscopy ${ }^{\mathrm{a}}$

\begin{tabular}{ll}
\hline 1. & Appropriate indication \\
2. & Use of recommended postpolypectomy and postcancer resection surveillance intervals \\
3. & Cecal intubation rates \\
4. & Detection of adenomas in asymptomatic individuals (screening) \\
5. & Number and distribution of biopsy samples in ulcerative colitis and Crohn's colitis surveillance \\
6. & Postpolypectomy bleeding managed non-operatively \\
\hline
\end{tabular}

a Adapted from Ref. [2]

Table 2 Postcancer resection surveillance colonoscopy recommendations ${ }^{\mathrm{a}}$

1. Patients should receive a perioperative clearing colonoscopy to rule out synchronous lesions (either intraoperatively or within 6 months).

2. Patients undergoing curative resection for colorectal cancer should undergo a colonoscopy 1 year after the resection (or 1 year after the completion colonoscopy).

3. If the examination performed at 1 year shows normal results, then the interval before the next subsequent examination should be 3 years.

4. If that examination shows normal results, the interval should be 5 years.

5. Intervals may be shortened if adenoma findings warrant it or if there is evidence of hereditary non-polyposis colorectal cancer.

6. Examinations at 3- to 6-month intervals for the first 2 or 3 years should be considered after low anterior resection.

${ }^{a}$ Adapted from Ref. [3] 
Table 3 Indications for colonoscopy

\begin{tabular}{lc}
\hline Indication & No. of cases (\% of total) \\
\hline Screening & $143(26)$ \\
Nonacute GI bleeding & $127(23)$ \\
Polyp surveillance & $100(18)$ \\
Postcancer resection surveillance & $91(17)$ \\
Abdominal pain & $19(4)$ \\
Anemia & $14(3)$ \\
Abnormal radiographic finding & $10(2)$ \\
Change in bowel habits & $4(<1)$ \\
Clearing colonoscopy & $3(<1)$ \\
Rectal mass & $3(<1)$ \\
Others & $33(6)$ \\
\hline
\end{tabular}

GI gastrointestinal

for failure of cecal intubation included redundancy $(n=6)$, inability to get past strictures $(n=4)$, poor bowel preparation $(n=4)$, patient discomfort and intolerance $(n=2)$, and intentional early termination after tattooing of adenoma site $(n=1)$.

Of 91 completed postcancer resection surveillance colonoscopies, 89 (98\%) were performed within the recommended surveillance intervals. Two colonoscopies were performed at an earlier time than the recommended interval. None of the postcancer resection surveillance colonoscopies detected a metachronous carcinoma. Of the three clearing colonoscopies, two showed a synchronous neoplastic lesion (one tubulovillous adenoma and one tubulovillous adenoma with a focus of adenocarcinoma).

The colonoscopy findings are presented in Table 4. If two or more polyps were found in a single procedure, the colonoscopy result was classified according to the most advanced pathologically staged lesion. In 13 of the 541 completed colonoscopies, polyps were visualized that had not undergone a biopsy for various reasons, had undergone an unsuccessful biopsy, or had yielded insufficient tissue for pathology analysis. In completed colonoscopies $(n=$ 541 ), the detection rates were $36 \%$ for all polyps (benign and malignant), $22 \%$ for adenomatous polyps, and $4 \%$ for cancerous lesions (including eight nonpolypoid cancerous masses). Thus, the overall neoplastic lesion detection rate was $26 \%$. This rate increased to $29 \%$ for patients 50 years of age or older, whereas it was $5 \%$ for patients younger than 50 years. Our detection rate for neoplastic lesions in screening colonoscopies was $20 \%$ (28/143). Of the 303 polyps subjected to biopsy, $62 \%$ were neoplastic. Eight nonpolypoid masses also were detected, and all eight tested positive for cancer, one of which was prostate cancer.

Two major complications $(<0.4 \%)$ resulted from the colonoscopies: one postpolypectomy bleeding $(<0.2 \%)$ and one perforation $(<0.2 \%)$. There was no mortality. The postpolypectomy bleeding occurred in an 83-year-old man with multiple comorbidities. After being admitted, he received $2 \mathrm{U}$ of transfused packed red blood cells and was observed. He was discharged on hospital day 2. The colonic perforation occurred in a 74-year-old man. He was taken to the operating room, where he received a primary repair without diversion. Both patients were discharged home in stable condition.

\section{Discussion}

The role of endoscopy in a surgeon's practice is rapidly evolving. In addition to its established traditional use in the diagnosis and treatment of gastrointestinal diseases, the indications for its use are expanding. Current indications include endoscopic mucosal tumor resection, increasingly

Table 4 Colonoscopy results

\begin{tabular}{lccccc}
\hline & $n(\%)$ & $\begin{array}{l}\text { Benign } \\
\text { polyps } n(\%)\end{array}$ & $\begin{array}{l}\text { Adenoma } \\
n(\%)\end{array}$ & $\begin{array}{l}\text { Cancer } \\
n(\%)\end{array}$ & $\begin{array}{l}\text { Neoplastic } \\
\text { lesions } n(\%)\end{array}$ \\
\hline $\begin{array}{l}\text { Total } \\
\text { Ages (years) }\end{array}$ & 541 & $63(12)$ & $121(22)$ & $21(4)$ & $142(26)$ \\
Age $>50$ & $483(89)$ & $51(11)$ & $119(25)$ & $20(4)$ & $139(29)$ \\
Age $<50$ & $58(11)$ & $12(21)$ & $2(3)$ & $1(2)$ & $3(5)$ \\
Gender & & & & & \\
Male & $517(96)$ & $61(12)$ & $118(23)$ & $21(4)$ & $139(27)$ \\
Female & $24(4)$ & $2(8)$ & $3(13)$ & $0(0)$ & $3(13)$ \\
$\begin{array}{l}\text { Indications } \\
\text { Screening (including FH) }\end{array}$ & 143 & $15(10)$ & $23(16)$ & $5(3)$ & $28(20)$ \\
Polyp surveillance & 100 & $12(12)$ & $37(37)$ & $3(3)$ & $40(40)$ \\
CA surveillance & 91 & $15(16)$ & $31(34)$ & $0(0)$ & $31(34)$ \\
\hline
\end{tabular}


complex and aggressive early-stage neoplasm and cancer resection, among others. The recent interest in natural orifice transluminal endoscopic surgery (NOTES) offers further possibilities for treating extraintestinal diseases endoscopically.

Historically, surgeon-endoscopists have demonstrated the ability to perform colonoscopies well, with good overall performance and low complication rates. Reed et al. [5] presented a favorable complication rate of $0.10 \%$ among non-fellowship-trained surgeons, concluding that no specific fellowship training was required. Wexner et al. [6] performed a large prospective analysis of 13,580 colonoscopies that further demonstrated the surgeon's ability to perform endoscopies rapidly and successfully with low morbidity and mortality rates.

Recently, guidelines for colonoscopy quality indicators have been proposed by several entities including SAGES, ASGE [2] (Table 1), and ACS [3] (Table 2). The emphasis includes appropriate indications and other objective criteria such as an adenoma detection rate and a cecal intubation rate. We applied these guidelines in our study to determine the appropriateness and competency of the colonoscopies performed by surgeon-endoscopists at a Veterans Affairs Healthcare System. We found that surgeon-endoscopists were able to meet or exceed expected quality outcomes when the data were specifically examined across a set of quality indicators, as delineated below.

\section{Indications}

Less than $1 \%$ of our colonoscopies failed to meet guidelines for appropriate indications for colonoscopy as determined by ASGE after review of the published literature and expert consensus [4]. These "appropriate" indications do not demand strict adherence. Rather, they serve as a reminder that colonoscopies are invasive procedures with inherent risks that must be considered carefully.

In our study, four patients younger than 50 years received a screening colonoscopy although they were asymptomatic and had no family history. In two of these cases, the patient admitted to having poor follow-up evaluation by physicians, with neglect toward their overall health issues. Two colonoscopies were performed for patients with a small bowel obstruction, and one colonoscopy was performed as part of a workup for a patient with recurrent bacteremia of an unclear source.

Interestingly, screening made up a large portion of the indications for colonoscopy in our series. This differs from most colonoscopy series reported by surgeons, in which the majority of the colonoscopies are performed for rectal bleeding, cancer surveillance, or changes in bowel habits $[5,7,8]$.
Postcancer resection surveillance intervals

Using guidelines established by the ACS in collaboration with the U.S. Multi-Society Task Force on Colorectal Cancer [3], we determined that 89 of our 91 postcancer surveillance group were scoped within the recommended intervals. The two patients who did not receive a colonoscopy within the recommended surveillance intervals were scoped at a shorter interval than recommended. Of the three clearing colonoscopies performed, two identified synchronous neoplastic lesions. In the 91 postcancer resection surveillance colonoscopies, we found no metachronous cancer. Rex et al. [3] reviewed 23 series of postcancer resection surveillance colonoscopy in the literature and found the collective average detection rate of metachronous cancer to be 1 per 157 .

\section{Cecal intubation rate}

Landmarks identified from intubation of the cecum generally are used as an end point in determining performance outcome. In our series, the cecum was successfully intubated in $97 \%$ of all colonoscopies. This rate compares favorably with expected completion rates quoted in the literature [9]. A 98\% completion rate was achieved in the screening subgroup. This is in line with the $97.7 \%$ cecal intubation rate achieved by Lieberman et al. [10] in their series of VA patients. By comparison, the expected cecal intubation rates are $90 \%$ for all colonoscopies and $95 \%$ for screening colonoscopies [2].

\section{Adenoma detection}

In our series, the overall adenoma detection rate was $26 \%$, and the detection rate for all polyps was $36 \%$. These numbers mirror the detection rates obtained by Wexner et al. [6] in their large prospective series of 13,580 colonoscopies. As expected, the adenoma detection rate was much higher for patients older than 50 years (29\% vs 5\% for patients younger than 50 years). Among our limited number of women, the adenoma detection rate was $13 \%$, less than half that for men $(27 \%)$.

In our sample of 143 screening studies, neoplastic lesions (adenomas + cancer) were detected in $19.6 \%$ of all screening colonoscopies. This rate increased to $20.5 \%$ when corrected for patients younger than 50 years and for women. By comparison, Goldenberg et al. [11] performed screening colonoscopies for 55 patients recruited from an academic general surgery practice. The polyp detection rate was $18 \%$, and the adenoma detection rate was $11 \%$. Rex et al. [2] report adenoma prevalence rates of at least $25 \%$ for men older than 50 years. 
The literature shows a wide variation in adenoma detection between practices and practicioners [12]. Barclay et al. [13] found an overall detection rate of $23.5 \%$ for neoplastic lesions in all patients screened by a group of 12 experienced gastroenterologists. However, this detection rate differed greatly between practitioners, ranging from $9.4 \%$ to $32.7 \%$. Barclay et al. [13] found a direct correlation between withdrawal time and the adenoma detection rate. Data on withdrawal time were not available to us through ProVation MD.

Inflammatory bowel disease surveillance

Due to the limited number of colonoscopies performed for patients with inflammatory bowel disease in our series $(n=$ 4), the study was underpowered to address this quality indicator.

\section{Complications}

In our series, two major complications occurred: one postpolypectomy bleeding requiring intervention $(<0.2 \%)$ and one colonic perforation $(<0.2 \%)$ surgically repaired using a primary anastomosis without diversion. There was no mortality. The ASGE reports a postpolypectomy bleeding risk of less than $1 \%$. This risk ranges from $0.07 \%$ [5] to 3\% [14] across the literature. Anderson et al. [15] reported a $0.19 \%$ perforation rate in 10,486 colonoscopies. Iqbal et al. [16] performed a retrospective review of 78,702 colonoscopies in the surgical literature, finding a perforation rate of only $0.084 \%$. Therefore, our complication rate, including perforations and bleeding, was consistent with published data.

Overall, using specific quality indicators for comparison, we confirmed through our study that surgeons demonstrate the ability to perform colonoscopy well, with good performance outcomes and a high level of safety. One weakness of our study was its inability to report on withdrawal time. Also, it would be interesting to apply these same quality indicators to surgical residents in their performance of colonoscopy through their years of training.

In conclusion, surgeon-endoscopists demonstrate proficiency in performing colonoscopies according to proposed guidelines. With the increased requirement of surgical training for colonoscopies, further studies are needed to determine whether these surgeon-endoscopists then can adequately train residents in these skills.
Open Access This article is distributed under the terms of the Creative Commons Attribution Noncommercial License which permits any noncommercial use, distribution, and reproduction in any medium, provided the original author(s) and source are credited.

\section{References}

1. http://www.acgme.org

2. Rex DK, Petrini JL, Baron TH, Chak A, Cohen J, Deal SE, Hoffman B, Jacobson BC, Mergener K, Petersen BT, Safdi MA, Faigel DO, Pike IM, ASGE/ACG Taskforce on Quality in Endoscopy (2006) Quality indicators for colonoscopy. Am J Gastroenterol 101:873-885

3. Rex DK, Kahi CJ, Levin B, Smith RA, Bond JH, Brooks D, Burt RW, Byers T, Fletcher RH, Hyman N, Johnson D, Kirk L, Lieberman DA, Levin TR, O'Brien MJ, Simmang C, Thorson AG, Winawer SJ (2006) Guidelines for colonoscopy surveillance after cancer resection: a consensus update by the American Cancer Society and U.S. Multi-Society Task Force on Colorectal Cancer. CA Cancer J Clin 56:160-167

4. ASGE (2000) Appropriate use of gastrointestinal endoscopy. Gastrointest Endosc 52:831-837

5. Reed DN Jr, Collins JD, Wyatt WJ, Hull JE, Patton ML, Dahm SO, Dabideen HH, Hudson JC, Allen DB (1992) Can general surgeons perform colonoscopy safely? Am J Surg 163:257-259

6. Wexner SD, Garbus JE, Singh JJ SAGES, Colonoscopy Study Outcomes Group (2001) A prospective analysis of 13, 580 colonoscopies: reevaluation of credentialing guidelines. Surg Endosc $15: 251-261$

7. Wexner SD, Eisen GM, Simmang C (2002) Principles of privileging and credentialing for endoscopy and colonoscopy. Surg Endosc 16:367-369

8. Wexner SD, Forde KA, Sellers G, Geron N, Lopes A, Weiss EG, Nogueras JJ (1998) How well can surgeons perform colonoscopy? Surg Endosc 12:1410-1414

9. Marshall JB, Barthel JS (1993) The frequency of total colonoscopy and terminal ileal intubation in the 1990s. Gastrointest Endosc 39:518-520

10. Lieberman DA, Weiss DG, Bond JH, Ahnen DJ, Garewal H, Chejfec G (2000) Use of colonoscopy to screen asymptomatic adults for colorectal cancer. Veterans Affairs Cooperative Study Group 380. N Engl J Med 343:162-168

11. Goldenberg EA, Khaitan L, Huang IP, Smith CD, Lin E (2006) Surgeon-initiated screening colonoscopy program based on SAGES and ASCRS recommendations in a general surgery practice. Surg Endosc 20:964-966

12. Chen SC, Rex DK (2007) Endoscopist can be more powerful than age and male gender in predicting adenoma detection at colonoscopy. Am J Gastroenterol 102:856-861

13. Barclay RL, Vicari JJ, Doughty AS, Johanson JF, Greenlaw RL (2006) Colonoscopic withdrawal times and adenoma detection during screening colonoscopy. N Engl J Med 355:2533-2541

14. Vernava AM III, Longo WE (1996) Complications of endoscopic polypectomy. Surg Oncol Clin North Am 5:663-673

15. Anderson ML, Pasha TM, Leighton JA (2000) Endoscopic perforation of the colon: lessons from a 10-year study. Am J Gastroenterol 95:3418-3422

16. Iqbal CW, Chun YS, Farley DR (2005) Colonoscopic perforations: a retrospective review. J Gastrointest Surg 9:1229-1235 